\title{
Erratum to: Effectiveness of observation-domain sidereal filtering for GPS precise point positioning
}

\author{
Christopher Atkins $^{1} \cdot$ Marek Ziebart ${ }^{1}$
}

Published online: 15 August 2015

(C) Springer-Verlag Berlin Heidelberg 2015

\section{Erratum to: GPS Solut \\ DOI 10.1007/s10291-015-0473-1}

Unfortunately, some errors occurred in the original publication of the article. The authors apologize to the editors and readers for an error in Figure 5. The new version of the figure indicates that the value 86,140 should be added to each of the y-axis tick labels (Fig. 5).

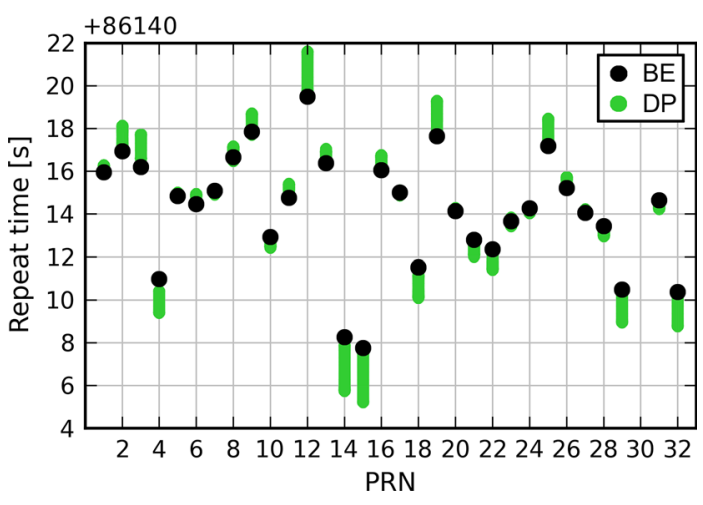

Fig. 5 Orbit repeat times calculated using elements in the broadcast ephemeris (BE) and the ranges of repeat times calculated by the dot product (DP) method for each GPS satellite PRN tracked at UCL on September 3, 2013

The online version of the original article can be found under doi:10.1007/s10291-015-0473-1.

\section{Christopher Atkins}

ucescat@ucl.ac.uk

1 Department of Civil, Environmental and Geomatic Engineering, University College London, Gower Street, London, UK 